\title{
A construção do conceito de resiliência em psicologia: discutindo as origens ${ }^{1}$
}

\author{
Juliana Mendanha Brandão² \\ Centro Universitário de Belo Horizonte, Belo Horizonte-MG, Brasil \\ Miguel Mahfoud \\ Ingrid Faria Gianordoli-Nascimento \\ Universidade Federal de Minas Gerais, Belo Horizonte-MG, Brasil
}

\begin{abstract}
Resumo: Este artigo apresenta um estudo teórico sobre resiliência que investiga, na literatura nacional e internacional, a forma como pesquisadores concebem o conceito e suas origens. Reconstituímos a história do conceito, estudamos a resiliência no campo da resistência dos materiais e da etimologia e questionamos a noção de que o termo/conceito "resiliência" teria sido tomado da física. Concluímos que as concepções de resiliência adotadas pelos pesquisadores - se ela é entendida como resistência ao estresse ou se é relacionada a processos de recuperação e superação - relacionam-se com o entendimento de que eles têm a respeito das origens da mesma.
\end{abstract}

Palavras-chave: resiliência (psicologia), formação de conceito, etimologia.

\section{The construction of the concept of resilience in psychology: discussing the origins of resilience}

\begin{abstract}
This article is a theoretical study that investigates resilience conceptions and its origins in national and international literature. We reconstituted the history of the concept; we studied the resilience in the field of strength of materials and etymology and we query the notion that the term/concept of "resilience" would have came from physics. We conclude that the resilience concepts adopted by researchers (if it is understood as stress resistance or as processes of recovery) are related with the understanding that they have about its origins.
\end{abstract}

Keywords: resilience (psychological), concept formation, etimology.

\section{La construcción del concepto de resiliencia en psicología: cuestionando los orígenes}

\begin{abstract}
Resumen: Este artículo es un estudio teórico sobre la resiliencia que hace una investigación, en la literatura nacional e internacional, acerca de la forma que los investigadores conciben el concepto y sus orígenes. Reconstituimos la historia del concepto, estudiamos la resiliencia en el campo de la resistencia de materiales y de la etimología y cuestionamos la noción de que la resiliencia (psicológica) ha sido originada en las ciencias exactas. Llegamos a la conclusión de que los conceptos de resiliencia adoptados por los investigadores (si entendida como resistencia al estrese o si está relacionada con los procesos de recuperación y superación) se relacionan con la comprensión que ellos tienen acerca de los orígenes del concepto.
\end{abstract}

Palabras clave: resiliencia (psicología), formación de concepto, etimología.

$\mathrm{Na}$ passagem da década de 1970 para 1980, pesquisadores americanos e ingleses voltaram sua atenção para o fenômeno das pessoas que permaneciam saudáveis apesar de expostas a severas adversidades. Chamaram inicialmente essas pessoas de invulneráveis e o fenômeno, de invulnerabilidade, como o termo que seria mais tarde substituído por resiliência.

Nas primeiras pesquisas sobre resiliência, pesquisadores de várias partes do mundo se apropriaram do tema, estudando-o a partir de diferentes perspectivas que são,

\footnotetext{
1 Este texto foi revisado seguindo o Acordo Ortográfico da Língua Portuguesa (1990), em vigor a partir de $1^{\circ}$ de janeiro de 2009. Este artigo é derivado da Dissertação de Mestrado Resiliência: de que se trata? $O$ conceito e suas imprecisões da primeira autora sob orientação de Miguel Mahfoud e Ingrid Faria Gianordoli-Nascimento, defendida em agosto de 2009, na Universidade Federal de Minas Gerais, junto ao Programa de Pós-graduação em Psicologia.

${ }^{2}$ Endereço para correspondência:

Juliana Mendanha Brandão. Rua Oriente, 672, apto 302. CEP 30.220-270.

Belo Horizonte-MG, Brasil.E-mail: julianabrandao6@hotmail.com
}

atualmente, organizadas por alguns autores (Fantova, 2008; Ojeda, 2004), em três correntes: a norte-americana ou anglosaxônica, a europeia e a latino-americana. A corrente norteamericana seria mais pragmática, mais centrada no indivíduo, tomando como avaliação da resiliência dados observáveis e quantificáveis, comumente com enfoque behaviorista ou ecológico transacional. A resiliência, aqui, surge como produto da interação entre o sujeito e o meio em que está inserido. A europeia teria uma perspectiva ética, mais relativista, com enfoque comumente psicanalítico, tomando a visão do sujeito como relevante para a avaliação da resiliência. De acordo com Fantova, para esta corrente, a resposta do sujeito às adversidades transcende os fatores do meio, é "tecida" a partir da dinâmica psicológica da pessoa, o que possibilita uma narrativa íntima e uma narrativa externa sobre a própria vida. Já a corrente latino-americana é mais comunitária, enfocando o social como resposta aos problemas do sujeito em meio às adversidades.

Em nossa pesquisa, observamos que, além da diferença nas perspectivas adotadas por pesquisadores dessas citadas 
correntes, há também, entre pesquisadores anglo-saxões e aqueles falantes de línguas latinas, diferenças na maneira de se entender e apresentar as origens do tema e diferenças em suas concepções de resiliência. Pesquisadores falantes de línguas latinas (incluindo os brasileiros) apontam que o termo/conceito "resiliência" teria sido tomado das ciências exatas, mais especificamente do campo da resistência dos materiais, enquanto os pesquisadores precursores do tema, os ingleses e norte-americanos, nada dizem a respeito dessa origem (Assis, Pesce, \& Avanci, 2006; Cyrulnik, 2001; Junqueira \& Deslandes, 2003; Luthar \& Zelazo, 2003; Masten, 2001; Poletto \& Koller, 2006, 2008; Rutter, 1985, 1993b; Trombeta \& Guzzo, 2002; Werner \& Smith, 1989, 1992; Yunes, 2001, 2003, 2006; entre muitos outros). Em relação às concepções adotadas sobre o tema, percebemos que, de modo geral, ingleses e norte-americanos entendem a resiliência como resistência ao estresse, enquanto brasileiros e pesquisadores falantes de línguas latinas têm uma concepção que entende a resiliência ora como resistência ao estresse, ora como associada a processos de recuperação e superação de abalos emocionais causados pelo estresse.

Com o objetivo de entendermos a causa das diferenças das concepções adotadas e o porquê da disparidade de entendimento sobre as origens da resiliência, foi realizada uma investigação no campo da resistência dos materiais, já que alguns autores dizem que a resiliência para a psicologia teria sido tomada daí, e na etimologia, para entender como a diferença das línguas dos pesquisadores poderia influenciar em suas concepções. Por fim, fomos buscar a história dos estudos sobre o tema, em textos latinos e anglo-saxões, o que nos permitiu entender como o conceito resiliência em psicologia foi construído e como essa construção afetou as concepções que os pesquisadores têm sobre o tema.

\section{Buscando o entendimento por meio da física}

Na literatura brasileira, pode-se dizer que há um consenso a respeito do conceito da resiliência ser originário da física ou do termo "resiliência" ter sido "importado" dessa disciplina (Assis e cols., 2006; Balancieri, 2007; CoutoOliveira, 2007; Junqueira \& Deslandes, 2003; Libório, Castro, \& Coêlho, 2006; Poletto, 2007; Poletto \& Koller, 2006, 2008; Souza \& Cerveny, 2006a, 2006b; Trombeta \& Guzzo, 2002; Yunes, 2003; Yunes, Mendes, \& Albuquerque, 2005; Yunes \& Szymanski, 2001, entre outros). Se tantos autores da psicologia apontam para a origem física do termo e do conceito "resiliência", torna-se importante entender como essa ciência trata o assunto.

Nas ciências exatas, o termo integra os estudos sobre resistência dos materiais e já era usado desde, pelo menos, 1807, quando o inglês Thomas Young (conforme citado por Timoshenko, 1953) publicou a obra em que a noção de módulo de elasticidade foi introduzida pela primeira vez. Segundo Timoshenko, nesta obra, Young fala de resiliência ao apresentar uma discussão sobre fraturas de corpos elásticos produzidas por impacto. O significado de resiliência para esse pesquisador não é o mesmo dos dias atuais, embora guarde semelhanças. Atualmente, para a disciplina resistência dos materiais, a resiliência é definida como a capacidade de um material de "absorver energia na região elástica" (Nash, 1982, p. 5), sendo essa capaz de voltar à forma original, quando finda a causa de sua deformação (Pinto, 2002). Beer e Johnston (1981/1989) explicam que "a capacidade do material estrutural suportar um impacto sem ficar deformado permanentemente depende de sua resiliência" (p. 522). Físicos e engenheiros utilizam a noção de módulo de resiliência para calcular a quantidade máxima de energia que um dado material pode absorver ao ser submetido a determinado impacto, deformando-se sem se romper e voltando posteriormente à forma primitiva. Tal noção relaciona-se ao limite de elasticidade do material.

Observamos que a ideia que uma das concepções que a psicologia tem da resiliência - de modo geral, capacidade para se recuperar de abalos sofridos ou de se abalar e voltar ao que se era antes do abalo - tem mais a ver com o conceito físico da elasticidade do que propriamente de resiliência. Isso porque a elasticidade seria a característica dos materiais de se deformarem e voltarem à sua forma original, após o fim da causa da deformação (Pinto, 2002). Para que se deformem sem se romper, é necessária a resiliência que implica na absorção da energia do impacto.

Mas nem tudo que resiste a pressões ou a abalos apresenta resiliência, pois há materiais que sob pressão não se deformam e, nesses casos, nem absorveriam a energia do impacto, sendo considerados resistentes, mas não elásticos. Quando um material resiste a um impacto, deformando-se pouco ou nada, ele é considerado rígido (Amaral, 2002). Este material, após certo limite de força aplicada sobre ele, se rompe de maneira irreversível, sem ter havido deformação. Um material elástico, por sua vez, também pode se romper ou sofrer outro tipo de deformação permanente, mas somente depois de ultrapassado seu limite de elasticidade e seu "módulo de resiliência", ou seja, a quantidade de energia passível de ser absorvida.

A partir desse entendimento dos conceitos da resistência dos materiais, caso se quisesse transpor de forma mais fidedigna o conceito de resiliência da física para a psicologia ou as ciências humanas estudarem, ao se focalizar a resiliência das pessoas, os estudos deveriam investigar o quanto as pessoas poderiam suportar de pressão, ou de estresse, antes de apresentarem abalo psicopatológico irreversível. Já se os estudos quisessem observar como as pessoas se abalam, se transformam sob uma pressão e se recuperam posteriormente, eles estariam investigando a elasticidade (psicológica) humana. Com isso, parece que, se o termo/conceito de resiliência usado pela psicologia foi originado na física, na resistência dos materiais, ele foi transposto de maneira imprecisa, pois se relaciona mais com o conceito de elasticidade do que de resiliência dos materiais.

Além dessas observações sobre os conceitos físicos, chamou a atenção o fato de que, em seis livros pesquisados 
sobre resistência dos materiais, ampla e atualmente usados, o assunto não aparece em dois (Amaral, 2002; Pinto, 2002), há poucas linhas dedicadas ao conceito em três (Beer \& Johnston, 1981/1989; Nash, 1982; Silva, 1974) e, no livro do autor mais importante da área (Timoshenko, 1966/1976), aparece somente em nota de rodapé (p. 312). Com isso, se tem a impressão de que, hoje, o termo "resiliência" é mais utilizado pelas ciências humanas e pela psicologia do que pelas ciências exatas. E parece pouco provável que um assunto que, nas ciências exatas, seja dotado de tão pouca significância tenha ultrapassado o limite de uma área de conhecimento para gerar interesse dos pesquisadores da psicologia.

\section{Origens etimológicas da resiliência}

Já em relação às origens etimológicas, pode-se dizer que a palavra "resiliência" comporta a ideia, presente na física, de um retorno ao que se era. A palavra vem do latim resilio, resilire. Resilio, de acordo com dois dicionários latim-português (Faria, 1967; Saraiva, 2000), seria derivada de re (partícula que indica retrocesso) e salio (saltar, pular), significando saltar para trás, voltar saltando.

No Brasil, o termo "resiliência", até ser utilizado, a partir do fim da década de 1990, nos estudos de psicologia e se espalhar para um público leigo por meio de matérias de autoajuda veiculadas na mídia, era desconhecido da maior parte da população. Não fazia parte do vocabulário coloquial brasileiro. E o que se poderia saber sobre ele nos dicionários e o que reflete o uso que os falantes da língua fazem de uma palavra era seu significado técnico ligado à física. O Novo Dicionário Aurélio da Língua Portuguesa (Ferreira, 1986, p. 1493), por exemplo, traz as seguintes definições para a palavra "resiliência": "Resiliência [do ingl. resilience] S.f. 1. Fís. Propriedade pela qual a energia armazenada em um corpo deformado é devolvida quando cessa a tensão causadora de uma deformação elástica. 2. Fig. Resistência ao choque".

$\mathrm{O}$ oposto parecia acontecer com as palavras resilience e resiliency na língua inglesa. Ao que tudo indica, provavelmente há mais de 30 anos, elas já faziam parte do vocabulário coloquial de falantes de língua inglesa, com uma significação menos "técnica", menos ligada à física, e mais relacionada a fenômenos humanos. Yunes (2001, 2003, 2006), buscando também a significação para a resiliência em dicionários de inglês (Longman) e português (Novo Aurélio), já havia notado essa diferença na atribuição de significados das duas línguas. Ela apontou que o dicionário de inglês que examinou coloca a definição ligada a fenômenos humanos em primeiro plano, confirmando, na língua inglesa, uma maior familiaridade ou prioridade para o uso do termo nesse tipo de fenômeno. Essa maior familiaridade da língua inglesa com a palavra resiliência fica muito evidente, quando se observam dicionários bilíngues em suas duas versões: inglês-português e português-inglês. Os conhecidos dicionários Michaelis (Novo Michaelis Dicionário Ilustrado, 1971; The New Michaelis Illustrated Dictionary, 1961) e Oxford
(Fowler, Fowler, \& Allen, 1990; The Oxford Portuguese Dictionary, 2002) não apresentam a palavra resiliência, para ser traduzida do português para o inglês, mas apresentam as palavras resilient que corresponde ao adjetivo "resiliente", e resilience/resiliency, correspondente à resiliência, para serem traduzidas para o português. Oxford diz que, enquanto resilient significa "elástico" ou "resistente", resilience quer dizer "elasticidade" ou "resistência". Michaelis traz como traduções para resilience, elasticidade e poder de recuperação; e, para resilient, "que ressalta, elástico, que se recupera prontamente, alegre, jovial" (p. 807). De forma semelhante, o dicionário Barsa (Houaiss \& Avery, 1970, p. 460) define resilience, -cy como "elasticidade, capacidade de rápida recuperação (saúde, bom humor, etc.)". Interessante notar que nenhum dos três dicionários citados aponta as palavras "resiliente" e "resiliência" como traduções para resilient e resiliency/resilience. É como se não existissem, no português, termos equivalentes aos vernáculos da língua inglesa.

Por outro lado, esses significados citados já estavam presentes em 1970, no dicionário de inglês Barsa e, em 1961, no Michaelis, pelas datas das edições examinadas. Isso nos faz perceber que, antes que os primeiros artigos que a psicologia produziu sobre o tema da resiliência aparecessem, a palavra já era, com muita probabilidade, usada pelos falantes da língua inglesa, o que não acontecia com os falantes brasileiros do português. Vai ao encontro dessa ideia, o fato de o próprio dicionário Aurélio, citado mais acima, atribuir a origem da palavra à língua inglesa, ainda que aponte uma origem latina para o verbo "resilir".

Sabemos que o fato de uma palavra constar em um dicionário não garante que ela seja usada realmente, mas serve como indicativo. Por outro lado, a palavra que não consta pode indicar seu pouco uso ou até sua inexistência na língua do dicionário.

\section{Discutindo a origem física da resiliência e a escolha do termo para os estudos}

Essas considerações a respeito da palavra "resiliência", na língua portuguesa e na inglesa, e do conceito na disciplina da resistência dos materiais se prestam a questionar a ideia de que a noção de resiliência para a psicologia veio da física ou das ciências exatas. Começamos esse questionamento após a observação de que tal origem física só é relatada pela literatura brasileira e por alguns outros autores de língua latina, mas não é dito em nenhum momento pelos precursores das pesquisas (anglo-saxões) e pelos principais pesquisadores internacionais sobre o tema, como Michael Rutter, Norman Garmezy, Ann Masten, Emmy Werner e Ruth Smith, Michael Ungar, Edith Grotberg, Suniya Luthar, entre outros.

Pelo menos no Brasil, é interessante notar que isso começou a ser propagado de maneira maciça desde que Maria Ângela Mattar Yunes (Yunes, 2001, 2003, 2006; Yunes \& Szymanski, 2001, 2005) começou a publicar os textos em que dá a entender que a noção para a psicologia viria da física, 
embora, nem sempre, afirme isso categoricamente. A autora fala do tema em relação à ciência exata, de sua origem e significado neste campo de conhecimento e das conceituações para a física, trazidas em dicionários. Em alguns textos, essa autora alerta para o risco na transposição do conceito da física para as ciências humanas (Yunes \& Szymanski, 2001, 2005).

Apartirdessaspublicações, quesetornaramreferenciais, quase todos os autores brasileiros interessados no tema passaram a reproduzir essas informações relacionadas ao campo das ciências exatas, citando Yunes, mas afirmando mais explicitamente que a resiliência da psicologia tem sua origem na física (Assis e cols., 2006; Balancieri, 2007; Couto-Oliveira, 2007; Junqueira \& Deslandes, 2003; Poletto, 2007; Poletto \& Koller, 2006, 2008; Souza \& Cerveny, 2006a, 2006b; Yunes e cols., 2005; entre outros), ainda que alguns pesquisadores já problematizem a comparação das definições da física, quando aplicadas a fenômenos humanos. Os poucos textos sobre resiliência que existiam no país, antes dessas publicações de Yunes, não traziam esses dados, o que pode ser percebido na publicação Hutz, Koller e Bandeira (1996).

Mas se os pesquisadores de língua latina atribuem às ciências exatas o termo e/ou o conceito da resiliência, por outro lado, os autores de língua inglesa não se preocupam em explicar a origem do termo resiliência em seus trabalhos. Não atribuem à física o uso do termo, embora às vezes utilizem, para ilustrar suas ideias, símiles que usam a constituição física de algum material.

Um exemplo interessante da diferença na atribuição das origens do tema entre autores anglo-saxões e latinos aparece em um texto do pesquisador Michael Rutter. Esse autor, precursor dos estudos, referência importante para a psicologia e psiquiatria, publicou, em 1993 (Rutter, 1993a), no Journal of Adolescent Health, o texto Resilience: Some conceptual considerations, onde não disse que o termo resiliência teria vindo da física. No entanto, na versão em espanhol deste artigo (Rutter, 1993b) que é apresentada nesse mesmo número da revista, o tradutor acrescentou ao texto uma nota de rodapé que traz a definição da física para a resiliência e explica que ela é uma noção afim ao conceito psicológico e, por isso, o mesmo termo é usado nas duas situações. Mas Rutter não afirma isso em nenhum momento.

A partir do que foi apresentado, nos perguntamos: se os pesquisadores que começaram a estudar o fenômeno da resiliência e escolheram esse termo para nomeá-lo não atribuem uma origem física ao que estudam, por que os autores de língua latina o fazem?

Parece que o fato de a palavra "resiliência" não fazer parte do vocabulário brasileiro coloquial ou do vocabulário de falantes de outras línguas latinas gerou uma necessidade de entender e justificar então de onde ela teria vindo. Tendo sido encontrado o conceito da física e o termo não ser conhecido fora deste âmbito de conhecimento, pareceu plausível supor que a ideia de resiliência para a psicologia teria vindo da ciência exata. E, no Brasil, como tal origem foi divulgada por uma pesquisadora respeitada, ela passou a ser considerada um fato.

Mas para os precursores dos estudos da resiliência, falantes do inglês, a palavra já era conhecida - fora do âmbito da resistência dos materiais - e provavelmente foi escolhida por ser considerada adequada para designar os fenômenos que eram estudados e que abrangiam capacidade de resistência a pressões e estresses, processos de recuperação, regeneração, adaptação, características de personalidades flexíveis e moldáveis às circunstâncias.

\section{A resiliência e o "espírito do tempo": contingências históricas}

Segundo nossa pesquisa, os estudos da resiliência começaram a emergir, em massa, em investigações de norte-americanos e ingleses, no final da década de 1970 e, principalmente, início da década de 1980, a partir de contingências históricas e sócio-culturais que provocaram uma convergência de interesses e objetos de pesquisa de diversas áreas da psicologia. Houve, então, uma mudança de paradigma na psicologia que se deu pela passagem da chamada abordagem ou enfoque de risco para o que depois foi chamado enfoque da resiliência.

Para Munist e cols. (1998), os dois enfoques são consequência da aplicação do método epidemiológico aos fenômenos sociais. Enquanto

o enfoque do risco centra-se na enfermidade, no sintoma e naquelas características que se associam a uma elevada probabilidade de dano biológico ou social, [o enfoque da resiliência] mostra que as forças negativas, expressas em termos de danos ou riscos, não encontram uma criança inerte na qual determinarão danos permanentes (Munist e cols., 1998, p. 10, tradução livre).

De acordo com Luthar e Zelazo (2003), a diferença básica dos dois enfoques é a natureza negativa ou positiva dos fatores que cada um focaliza. $\mathrm{Na}$ abordagem de risco, os resultados negativos do desenvolvimento e os fatores também negativos que nele interferem é que são focalizados, como a presença de distúrbios psicológicos e a doença mental de um dos pais. Já na abordagem da resiliência, dimensões tanto positivas quanto negativas são focalizadas nos resultados de um desenvolvimento e nos fatores que atuam sobre este.

Garmezy (1989), no prefácio do livro Vulnerable but invencible: A longitudinal study of resilient children and youth, de Werner e Smith, obra considerada por alguns um marco dos estudos da resiliência (Fantova, 2008; Garmezy, 1989; Infante, 2005; Melillo, 2005; Silva, Elsen, \& Lacharité, 2003; Silveira, 2006), fala de se estar vivendo, em 1982, ano em que foi publicado originalmente o livro, no limiar de um Zeitgeist. Goethe (conforme citado por Brozek \& Guerra, 2008, p. 10) define Zeitgeist como um "conjunto de opiniões 
que dominam um momento específico da história e que, sem nosso saber, ou inconscientemente, formam o pensamento de todos os que vivem em seu contexto".

Garmezy (1989) notou uma mudança no Zeitgeist, na passagem dos anos de 1970 para os de 1980, a partir da observação da proliferação de estudos de estresse e coping, feitos por pesquisadores de áreas diversas como psiquiatria, biologia do desenvolvimento, psicologia do desenvolvimento, psicopatologia e sociologia. Além disso, segundo o autor, palavras e expressões como "resiliência", "força do ego" (ego strenght), "resistência ao estresse", etc. foram se tornando cada vez mais frequentes na linguagem científica. Para Garmezy, a obra pioneira de Werner e Smith (1989), da qual ele escrevia o prefácio, era parte dessa nova emergência na ciência, pois examinava crianças em risco, sua vulnerabilidade, avançava examinando coping e crescimento e apontando que sempre havia crianças resilientes e "invencíveis" entre aquelas de alto risco.

Quando se diz que as pesquisadoras examinavam crianças em risco, se está referindo a crianças expostas aos chamados fatores de risco, definidos como influências potenciais para dificultar o desenvolvimento normal de um indivíduo (Werner \& Smith, 1992).

Já vulnerabilidade refere-se à "predisposição individual para o desenvolvimento de psicopatologias ou de comportamento ineficazes em situações de crise" (Hutz e cols., 1996, p. 80). Trombeta e Guzzo (2002, p. 32) esclarecem que "quanto mais proteção e menos risco, menor vulnerabilidade e quanto mais risco e menos proteção, maior vulnerabilidade", sendo importante esclarecer que proteção ou fatores de proteção relacionam-se com aquilo que altera, modifica ou aperfeiçoa a resposta de uma pessoa a possíveis ameaças ao seu desenvolvimento (Rutter, 1985).

Coping, por sua vez, como explicam Antoniazzi, Dell'Aglio e Bandeira (1998), "tem sido descrito como o conjunto das estratégias utilizadas pelas pessoas para adaptarem-se a circunstâncias adversas ou estressantes" (p. 273).

Voltando às origens dos estudos sobre a resiliência, podemos dizer que as ideias de Martineau (2001) são concordantes com as de Garmezy, pois a autora afirma que foi a partir dos mais de 1.040 estudos sobre coping e competência que as pesquisas sobre resiliência originaram-se, quando psicólogos infantis observaram a "anomalia" de crianças que aparentavam invulnerabilidade a traumas. Em sintonia com essas observações, Masten (2001), Masten e Coatsworth (1998), Masten e Powel (2007), Rutter (1985) e Waller (2001) também apontam que foi estudando crianças em risco de desenvolverem problemas psicopatológicos ou de comportamento, devido a circunstâncias genéticas ou ambientais que poderiam predispô-las a isso, que os pesquisadores começaram a perceber aquelas que estavam submetidas às mesmas condições de risco, mas se desenvolviam bem.

Werner e Smith (1989), por sua vez, afirmam que o advento de pesquisas longitudinais que acompanhavam populações desde o nascimento também pesou para que a psicologia pudesse olhar o desenvolvimento normal ou positivo das crianças, após anos de preocupação com patologias. Segundo as autoras, se os estudos retrospectivos feitos até então criavam a impressão de que determinados resultados negativos eram inevitáveis, os novos estudos provocaram um aumento da consciência sobre a capacidade de adaptação das crianças e suas habilidades de enfrentamento.

Isso porque os estudos retrospectivos tomavam sujeitos que já apresentavam problemas no desenvolvimento e buscavam em sua história o que poderia ter provocado tal resultado. Ou seja, apenas os riscos, a psicopatologia e o mau desenvolvimento eram focados. Já os estudos prospectivos e longitudinais tomavam para estudo sujeitos em situação de risco, que frequentemente "surpreendiam", mostrando boa adaptação e bons resultados. A resiliência se mostrava nesses estudos que traziam essa "nova" metodologia.

Mas se o Zeitgeist ou "espírito do tempo" contribuiu para provocar, no fim dos anos de 1970, uma mudança de foco na psicologia e a emergência dos estudos da resiliência, o próprio Zeitgeist foi também formado a partir da conjuntura sócio-histórica do citado período. Dessa forma, devemse procurar quais contingências históricas e socioculturais, atuantes principalmente nos países precursores dos estudos - Estados Unidos e Inglaterra -, teriam transformado o "espírito do tempo" em que começaram a surgir as pesquisas da resiliência.

Masten e Coatsworth (1998) situam a origem dos estudos sobre a resiliência em algumas condições sócio-históricas, que teriam emergido nos Estados Unidos, nos anos de 1970, e que ameaçavam o desenvolvimento infantil saudável. Segundo os autores, entre outras questões, o aumento de casos de divórcio, de gravidezes na adolescência, de abuso de crianças e de problemas como abuso de drogas e violência representava um pouco dos riscos aos quais as crianças estavam submetidas.

Os autores relacionaram tais condições sócio-históricas com o florescimento das pesquisas sobre resiliência, pois, segundo eles, foi investigando os riscos aos quais a infância estava submetida que o citado fenômeno foi observado. Isso porque se tornou particularmente importante entender como crianças ameaçadas em seu desenvolvimento poderiam alcançar sucesso ou demonstrar competência.

Como, para esses autores, estudar resiliência representa entender como crianças apresentam bom desenvolvimento após superar adversidades, neste momento histórico, em que a sociedade americana sentia que seu futuro estava ameaçado pelos riscos que sua infância corria, tornava-se importantíssimo entender como se poderia escapar às ameaças e aos riscos. E aí, os estudos da resiliência se multiplicaram.

A informação histórica, trazida por Masten e Coatsworth (1998) sobre os anos em que os estudos da resiliência iniciaram sua proliferação, está de acordo com a descrição que o historiador Eric Hobsbawm (1994/2001) faz do período em seu livro "Era dos Extremos: O breve século XX": após uma "Era de Ouro", acontecida no pós-guerra até mais ou menos 
1975, o mundo vivenciou um período de crise em que houve desemprego em massa, a pobreza e as desigualdades sociais e econômicas se aguçaram. Por outro lado, havia menos inquietação social, porque os países capitalistas ricos proviam ao seu povo sistemas de previdência e seguridade social generosos.

Além disso, os tempos passaram a ser marcados pelo individualismo que substituiu paulatinamente a coletividade característica de uma era anterior em que a vida, o trabalho e os prazeres eram vivenciados em massa. Tal individualismo é consequência das profundas transformações sociais atreladas ao extraordinário crescimento econômico pelo qual passou o mundo na anterior "Era de Ouro". É consequência, também, da tecnologia emergente acessível às massas, agora em melhor situação econômica, e da lógica do mercado. A televisão, o vídeo e o telefone são exemplos de novas tecnologias que fizeram com que o homem moderno deixasse de compartilhar a vida em público.

Por fim, ao longo dos anos de 1980, o mundo viu a Guerra Fria perder o sentido enquanto o bloco socialista, encabeçado pela URSS, ruía, pondo fim à utopia da coletividade altruísta que poderia prover as necessidades da humanidade por meio de uma divisão justa de riquezas. Com isso, as pessoas acabaram por perder as bases que sustentavam sua visão de mundo até então bipartido entre as forças do socialismo ou do capitalismo.

E nesse contexto de aumento de pobreza e riscos, de desmobilização social, de transformações de valores morais e de maior importância do indivíduo sobre a coletividade é que proliferaram os estudos da resiliência, entendida, nesse início, a partir de uma perspectiva bastante individualista.

Em diferentes linhas de pesquisa, profissionais de várias formações, observando crianças submetidas a outros fatores de risco, como alcoolismo, drogadição e doenças mentais de seus cuidadores, notaram aquelas que, contra todas as probabilidades, se desenvolviam satisfatoriamente.

Autores da época chamaram esses indivíduos de invulneráveis, invencíveis (Anthony \& Cohler, 1987). Mas como esses não seriam os termos mais adequados para os fenômenos que se tornavam visíveis, "resiliência" passou a nomeálos, e mais estudos sobre ela foram realizados.

\section{Considerações finais}

Neste artigo, apresentamos o que entendemos da história do conceito de resiliência e questionamos sua suposta origem física. Podemos fazer algumas considerações sobre a relação entre a forma como grupos de pesquisadores entendem as origens da resiliência e a concepção que adotam.

Vimos que pesquisadores "não anglo-saxões" atribuem uma origem na Física ao termo e/ou conceito "resiliência", o que não é mencionado pelos pesquisadores referenciais de língua inglesa. E é possível perceber que os estudiosos anglo-saxões adotam uma concepção de resiliência diferente daquela adotada por estudiosos falantes de línguas latinas.
Para a maioria dos anglo-saxões, com a exceção de alguns autores (Flach, 1991; Grotberg, 2005; Murphy, 1987; Walsh, 1998/2005), a resiliência é um fenômeno relacionado à resistência ao estresse e, sendo assim, são escolhidos como sujeitos de pesquisa pessoas que não se abalaram em situações adversas e demonstram o que eles chamam de competência. A noção de adaptação, em sentido de ajustamento social, está inserida nessa concepção. Já para os pesquisadores brasileiros e outros de língua latina, os estudos de resiliência estão relacionados aos fenômenos de resistência ao estresse, mas também aos de recuperação e de superação. Em consequência dessa concepção ambivalente do conceito, nesses estudos não anglo-saxões, são escolhidos como sujeitos de pesquisa tanto pessoas que se abalaram e se recuperaram quanto aquelas que permaneceram bem todo o tempo. Assim, estudam-se fenômenos diferentes sob a mesma nomenclatura, dando o nome genérico de resiliência a todos ou a qualquer um dos fenômenos.

Perguntamo-nos: por que um grupo de pesquisadores não tem dúvida de que a resiliência que estudam é a resistência ao estresse e o outro estuda dois fenômenos como se fossem um só?

Consideramos que a resposta se relaciona com o fato de que os pesquisadores anglo-saxões e os outros iniciaram seus estudos sobre a resiliência em pontos de partida distintos. Os anglo-saxões estavam estudando justamente o fenômeno de resistência ao estresse, ao qual chamavam invulnerabilidade, quando mudaram a nomenclatura para resiliência. Chamava-lhes a atenção a existência das pessoas que tinham toda a probabilidade de apresentar mau desenvolvimento, mas apresentavam-se bem. Em seus estudos sobre invulnerabilidade e resiliência, não estavam procurando entender pessoas que se recuperavam de traumas ou que se abatiam em situações de risco, mas depois ficavam bem. Ao longo do tempo, em sua maioria, continuaram a estudar basicamente o mesmo tipo de fenômeno, embora tenham avançado muito em suas teorizações.

Os brasileiros e os pesquisadores de língua latina, por sua vez, começaram seus estudos sobre o tema cerca de 20 anos depois dos americanos e ingleses, e seu ponto de partida foi a literatura anglo-saxônica (como não poderia deixar de ser, pois era a única disponível). Sendo assim, começaram a estudar resiliência como resistência ao estresse. No entanto, posteriormente, começaram a trazer definições de resiliência que incluíam o sentido de superação e começaram a estudar o fenômeno de recuperação.

Concluímos que a busca pelas origens do termo "resiliência" nas ciências exatas, o que não se deu nas pesquisas dos anglo-saxões, tenha influenciado essa "mudança de foco" dos estudos. Isso porque, para a resistência dos materiais, como já foi dito, a noção de resiliência está ligada ao conceito de elasticidade dos materiais que se deformam sob pressão, mas depois voltam à sua forma original, demonstrando poder de recuperação. Dessa maneira, como os pesquisadores não anglo-saxões da psicologia e das ciências sociais foram buscar 
uma base para seus estudos nas ciências exatas, nas quais a resiliência tem esse sentido de recuperação, levantamos a hipótese de que a concepção de recuperação que a resiliência passou a ter possa ter vindo dali.

É importante considerar, no entanto, em relação à resiliência entendida como possibilidade de recuperação que, atualmente, autores nacionais e internacionais de renome avançaram muito nessa concepção e concebem que a capacidade de resiliência vai muito além de se recuperar de um dano, pois implica uma superação do que se era, bem como crescimento pessoal (Assis e cols., 2006; Junqueira \& Deslandes, 2003; Silveira, 2006; Ungar, 2005; Walsh, 1998/2005, entre outros).

A diferença de concepções de resiliência traz consequências importantes para os projetos de intervenção social que utilizam o conceito. Os projetos advindos da concepção de resistência ao estresse objetivam proporcionar essa resistência ao máximo de pessoas possível e, para isso, potencializam os fatores de proteção e tentam minorar a ação dos fatores de risco. Esses projetos visam a conseguir um máximo de pessoas competentes e bem adaptadas que não se abalem diante das adversidades. Seus objetivos não estão voltados para os que já sucumbiram intentando recuperá-los. Por outro lado, projetos de resiliência baseados em concepções de recuperação e superação já se voltam aos que se mostram mais fragilizados diante de adversidades, com objetivos de fortalecê-los, recuperá-los e torná-los mais fortes.

Por tudo isso, consideramos fundamental que aqueles que estudam a resiliência entendam sobre a construção do conceito, considerando que essa se relaciona estreitamente com a concepção adotada.

\section{Referências}

Amaral, O. C. (2002). Curso básico de resistência dos materiais. Belo Horizonte: Artes Gráficas Formato.

Anthony, E. J., \& Cohler, B. J. (1987). The invulnerable child. New York: The Guilford Press.

Antoniazzi, A. S., Dell'Aglio, D. D., \& Bandeira, D. R. (1998). O conceito de coping: Uma revisão teórica [Versão eletrônica]. Estudos de Psicologia (Natal), 3(2), 273-294. Recuperado em 02 janeiro 2008, de http://www. scielo.br/scielo.php?script $=$ sci_issuetoc\&pid $=1413$ 294X19980002\&lng=pt\&nrm=iso

Assis, S. G., Pesce, R. P., \& Avanci, J. Q. (2006). Resiliência: Enfatizando a proteção dos adolescentes. Porto Alegre: Artes Médicas.

Balancieri, M. F. (2007). Promoção do processo de resiliência em enfermeiras: Uma possibilidade? Tese de doutorado não-publicada, Pontifícia Universidade Católica de São Paulo, São Paulo.

Beer, F. P., \& Johnston, E. R., Jr. (1989). Resistência dos materiais (P. P. Castilho, Trad.). São Paulo: McGrawHill. (Original publicado em 1981).
Brozek, J., \& Guerra, E. (2008). Que fazem os historiógrafos? Uma leitura de Josef Brozek [Versão eletrônica]. In R. H. Freitas(Org.), História da psicologia: Pesquisa, formação e ensino (pp. 4-20). Rio de Janeiro: Centro Edelstein de Pesquisas Sociais. Recuperado em 20 de junho de 2011, de http://www.bvce.org/LivrosBrasileirosDetalhes. asp?IdRegistro $=50$

Couto-Oliveira, V. (2007). Vida de mulher: Gênero, pobreza, saúde mental e resiliência. Dissertação de mestrado nãopublicada, Universidade de Brasília, Brasília, DF.

Cyrulnik, B. (2001). La maravilla del dolor: El sentido de la resiliencia (G. González-Zafra, Trad.). Barcelona: Granica.

Fantova, F. J. M. (2008). Resiliència $i$ voluntad de sentit em la promoció de la salut psicosocial em els docents: Capacitat de reconstrucció positiva a partir d'um context inicial d'adversitat. Estudi de cas em um institut d'educació secundària. Tese de doutorado nãopublicada, Facultat de Psicologia, Ciències de l'Educació i de l'Esport Blanquerna, Barcelona, Espanha.

Faria, E. (1967). Dicionário escolar latino-português (4a ed.). Rio de Janeiro: Departamento Nacional de Educação/Ministério da Educação e Cultura.

Ferreira, A. B. H. (1986). Novo dicionário Aurélio da língua portuguesa (2a ed.). Rio de Janeiro: Nova Fronteira.

Flach, F. (1991). Resiliência: A arte de ser flexível (W. Dupont, Trad.). São Paulo: Saraiva.

Fowler, H. W., Fowler, F. G., \& Allen, R. E. (1990). The concise Oxford dictionary of current english (8th ed.). Oxford, UK: Clarendon Press.

Garmezy, N. (1989). Foreword. In E. E. Werner \& R. S. Smith. Vulnerable but invincible: A longitudinal study of resilient children and youth (2th ed., pp. 13-19). New York: Adams, Bannister, Cox.

Grotberg, E. H. (2005). Introdução: Novas tendências em resiliência. In A. Melillo, E. N. S. Ojeda e cols. Resiliência: Descobrindo as próprias fortalezas (V. Campos, Trad., pp. 15-22). Porto Alegre: Artes Médicas.

Hobsbawm, E. (2001). Era dos extremos: O breve século XX, 1914-1991 (M. Santarrita Trad., 2a ed.). São Paulo: Companhia das Letras. (Original publicado em 1994).

Houaiss, A., \& Avery, C. S. (Orgs.). (1970). Novo dicionário Barsa de línguas inglesa e portuguesa (Vol. 1). Nova Iorque: Appleton-Century Crofts.

Hutz, C. S., Koller, S. H., \& Bandeira, D. R. (1996). Resiliência e vulnerabilidade em crianças em situação de risco. In S. H. Koller (Org.), Aplicações da psicologia na melhoria da qualidade de vida (Coletâneas da ANPEPP, 12, pp. 79-86). Rio de Janeiro: Associação Nacional de Pesquisa e Pós-Graduação em Psicologia.

Infante, F. (2005). A resiliência como processo: Uma revisão da literatura recente. In A. Melillo, E. N. S. Ojeda e cols. Resiliência: Descobrindo as próprias fortalezas. (V. Campos, Trad., pp. 23-38). Porto Alegre: Artmed. 
Junqueira, M. F. P. S., \& Deslandes, S. F. (2003). Resiliência e maus-tratos à criança [Versão eletrônica]. Cadernos de Saúde Pública, 19(1), 227-235. Recuperado em 10 outubro 2006, de www.scielo.br/pdf/csp/v19n1/14923. pdf

Libório, R. M. C., Castro, B. M., \& Coêlho, A. E. L. (2006). Desafios metodológicos para a pesquisa em resiliência: Conceitos e reflexões críticas. In D. D. Dell'Aglio, S. H. Koller, \& M. A. M. Yunes (Orgs.), Resiliência e psicologia positiva: Interfaces do risco à proteção (pp. 89-116). São Paulo: Casa do psicólogo.

Luthar, S. S., \& Zelazo, L. B. (2003). Research on resilience: An integrative review. In S. S. Luthar (Ed.), Resilience and vulnerability: Adaptation in the context of childhood adversities (2nd ed., pp. 510-549). New York: Cambridge University Press.

Martineau, S. (2001). The risky business of translating resiliency research into advocacy practice. Recuperado em 1 outubro 2007, de www.bcifv.org/ resources/ newsletter $/ 2001 /$ winter

Masten, A. S. (2001). Ordinary magic: Resilience process in development. American Psychologist 56(3), 227-238.

Masten,A. S., \& Coatsworth, J. D. (1998). The development of competence in favorable and unfavorable environments: Lessons from research on successful children. American Psychology, 53(2), 205-220.

Masten, A. S., \& Powell, J. L. (2007). A resilience framework for research, policy, and practice. In S. S. Luthar (Ed.), Resilience and vulnerability: Adaptation in the context of childhood adversities (2nd ed., pp. 1-25). New York: Cambridge University Press.

Melillo, A. (2005). Prefácio. In A. Melillo, E. N. S. Ojeda e cols. Resiliência: Descobrindo as próprias fortalezas (V. Campos, Trad., pp. 23-38). Porto Alegre: Artes Médicas.

Munist, M., Santos, H., Kotliarenco, M. A., Ojeda, E. N. S., Infante, F., \& Grotberg, E. (1998). Manual de identificación e promoción de la resiliencia [Versão eletrônica]. Washington, DC: Organización Panamericana de la salud. Recuperado em 08 setembro 2008, de www. paho.org/Spanish/HPP/HPF/ADOL/Resilman.PDF

Murphy, L. B. (1987). Further reflections on resilience. In E. J. Anthony \& B. J. Cohler (Eds.), The invulnerable child (pp. 84-105). New York: The Guilford Press.

Nash, W. A. (1982). Resistência dos materiais (G. E. O. Giacageia, Trad., 2a ed.). São Paulo: McGraw-Hill do Brasil.

Novo Michaelis dicionário ilustrado. (1971). (Vol. 2: português-inglês, 8a ed.). São Paulo: Melhoramentos.

Ojeda, E. N. S. (2004). Introducción: Resiliencia e subjetividad. In A. Melillo, E. N. S. Ojeda, \& D. Rodríguez (Orgs.), Resiliencia y subjetividad: Los ciclos de la vida (pp. 17-20). Buenos Aires: Paidós.

Pinto, J. L. T. (2002). Compêndio de resistência dos materiais. São José dos Campos, SP: UNIVAP.
Poletto, M. (2007). Contextos ecológicos de promoção de resiliência para crianças e adolescentes em situação de vulnerabilidade. Dissertação de mestrado não-publicada, Universidade Federal do Rio Grande do Sul, Porto Alegre.

Poletto, M., \& Koller, S. H. (2006). Resiliência: Uma perspectiva conceitual e histórica. In D. D. Dell'Aglio, S. H. Koller, \& M. A. M. Yunes (Orgs.), Resiliência e psicologia positiva: Interfaces do risco à proteção (pp. 19-44). São Paulo: Casa do Psicólogo.

Poletto, M., \& Koller, S. H. (2008). Contextos ecológicos: Promotores de resiliência, fatores de risco e proteção. Estudos de Psicologia (Campinas), 25(3), 405-416.

Rutter, M. (1985). Resilience in the face of adversity: Protective factors and resistance to psychiatric disorder. British Journal of Psychiatry, 147, 598-611.

Rutter, M. (1993a). La resiliencia: Consideraciones conceptuales. Journal of Adolescent Health, 14(8), 690696.

Rutter, M. (1993b). Resilience: Some conceptual considerations. Journal of Adolescent Health, 14(8), 626-631.

Saraiva, F. R. S. (2000). Novíssimo dicionário latinoportuguês (11a ed.). Rio de Janeiro: Livraria Garnier.

Silva, J. F., Jr (1974). Resistências dos materiais (4a ed.). Belo Horizonte: Ao Livro Técnico.

Silva, M. R. S., Elsen, I., \& Lacharité, C. (2003). Resiliência: Concepções, fatores associados e problemas relativos à construção do conhecimento na área. Paidéia (Ribeirão Preto), 13(26), 147-156.

Silveira, D. R. (2006). Osentido da resiliência: A contribuição de Viktor Emil Frankl. Dissertação de Mestrado nãopublicada, Universidade Federal de Minas Gerais, Belo Horizonte.

Souza, M. T. S., \& Cerveny, C. M. O. (2006a). Resiliência: Introdução à compreensão do conceito e suas implicações no campo da psicologia [Versão eletrônica]. Revista Ciências Humanas, 12(2), 21-29. Recuperado em 29 novembro 2010, de http://www.unitau.br/scripts/ prppg/humanas/download/Humanas\%202006\%202/ Pdf $/ 2 \%$ BA\%20art..pdf

Souza, M. T. S., \& Cerveny, C. M. O. (2006b). Resiliência psicológica: Revisão da literatura e análise da produção científica [Versão eletrônica]. Revista Interamericana de Psicologia, 40(1), 119-126. Recuperado em 29 novembro 2010, de www.psicorip.org/Resumos/PerP/ RIP/RIP036a0/RIP04013.pdf

The new Michaelis illustrated dictionary. (1961). (Vol. 1; Inglês-Português, 3th ed.). São Paulo: Melhoramentos.

The Oxford portuguese dictionary. (2002). (3rd ed.) New York: Oxford University Press.

Timoshenko, S. P. (1953). History of strength of materials: With a brief account of the history of theory of elasticity and theory of structures. New York: McGraw-Hill. 
Timoshenko, S. P. (1976). Resistência dos materiais (J. R. Carvalho, Trad., Vol. 1). Rio de Janeiro: Livros Técnicos e Científicos. (Original publicado em 1966)

Trombeta, L. H. A. P., \& Guzzo, R. S. L. (2002). Enfrentando o cotidiano adverso: Estudo sobre resiliência em adolescentes. Campinas, SP: Alínea.

Ungar, M. (2005). A thicker description of resilience. The International Journal of Narrative Therapy and Community Work, (3-4), 89-96. Recuperado em 4 março 2009, de www.resilienceproject.org/index. cfm? fuseaction=text.8str_cmID $=148$

Waller, M. A. (2001). Resilience in ecosystemic context: Evolution of the concept. American Journal of Orthopsychiatric, 71(3), 290-297.

Walsh, F. (2005). Fortalecendo a resiliência familiar (M. F. Lopes, Trad.). São Paulo: Roca. (Original publicado em 1998)

Werner, E. E., \& Smith, R. S. (1989). Vulnerable but invincible: A longitudinal study of resilient children and youth (2nd ed.). New York: Adams, Bannister, Cox.

Werner, E. E., \& Smith, R. S. (1992). Overcoming the odds: High risk children from birth to adulthood. London: Cornell University Press.

Yunes, M. A. M. (2001). A questão triplamente controvertida da resiliência em famílias de baixa renda. Tese de doutorado-não publicada, Pontifícia Universidade Católica de São Paulo, São Paulo.

Yunes, M. A. M. (2003). Psicologia positiva e resiliência: O foco no indivíduo e na família [Versão eletrônica]. Psicologia em Estudo, 8(No. Especial), 75-84. Recuperado em 12 outubro 2006, de www.scielo.br/pdf/ pe/v8nspe/v8nesa10.pdf

Yunes, M. A. M. (2006). Psicologia positiva e resiliência: O foco no indivíduo e na família. In D. Dell'Aglio, S. H. Koller, \& M. A. M. Yunes (Orgs.), Resiliência e psicologia positiva: Interfaces do risco à proteção (pp. 45-68). São Paulo: Casa do Psicólogo.

Yunes, M. A. M., Mendes, N. F., \& Albuquerque, B. M. (2005). Percepções e crenças de agentes comunitários sobre resiliência em famílias monoparentais pobres. Texto e Contexto: Enfermagem, 14(No. Especial), 24-31.

Yunes, M. A. M., \& Szymanski, H. (2001). Resiliência: Noção, conceitos afins e considerações críticas. In J. Tavares (Org.), Resiliência e educação (pp. 13-42). São Paulo: Cortez.

Yunes, M. A. M., \& Szymanski, H. (2005). Entrevista reflexiva e grounded-theory: Estratégias metodológicas para compreensão da resiliência em famílias [Versão eletrônica]. Revista Interamericana de Psicologia, 39(3), 1-8. Recuperado em 06 julho 2008, de http://www. psicorip.org/Resumos/PerP/RIP/RIP036a0/RIP03950. pdf
Juliana Mendanha Brandão é Professora do Centro Universitário Newton Paiva, Belo Horizonte-MG.

Miguel Mahfoud é Professor Associado do Departamento de Psicologia da Universidade Federal de Minas Gerais.

Ingrid Faria Gianordoli-Nascimento é Professora Adjunta do Departamento de Psicologia da Universidade Federal de Minas Gerais.
Recebido: 15/10/2009

$1^{a}$ revisão: $17 / 02 / 2010$

$2^{a}$ revisão: $22 / 11 / 2010$

Aceite final: 03/02/2011 